\title{
Effects of Buspirone on Anxiolytic Effects of Magnesium in Male Mice
}

\author{
Mahsa Hadipour Jahromy ${ }^{1 *}$, Golnar Golbaghi' ${ }^{2}$, Ahmad Jamshidi Mohajer ${ }^{1}$, \\ Fatemeh Kamali Poor ${ }^{1}$, Mahdieh Riazi ${ }^{1}$ \\ ${ }^{1}$ Department of Pharmacology, Medical Sciences Research Center, Faculty of Medicine, Islamic Azad University, \\ Tehran Medical Sciences Branch, Tehran, Iran \\ ${ }^{2}$ Department of Biology, North Branch, Islamic Azad University, Tehran, Iran \\ Email: ${ }^{\text {jahromymh@yahoo.com }}$
}

Received 19 April 2014; revised 28 May 2014; accepted 9 June 2014

Copyright (C) 2014 by authors and Scientific Research Publishing Inc.

This work is licensed under the Creative Commons Attribution International License (CC BY).

http://creativecommons.org/licenses/by/4.0/

(c) (i) Open Access

\begin{abstract}
Anxiolytic-like activity of magnesium chloride has been exhibited in the elevated plus-maze test in mice, in several studies. Buspirone is an anxiolytic psychoactive drug of the azapirone chemical class that is not related to benzodiazepines, unlike most drugs predominately used. The purpose of the present study was to examine interaction between magnesium (Mg) and buspirone as a partial agonist of $5-\mathrm{HT}_{1 \mathrm{~A}}$ receptors in producing anxiolytic-like activity in the elevated plus maze. The anxiolytic-like effect of $\mathrm{Mg}(50,100$ and $200 \mathrm{mg} / \mathrm{kg}$, orally), buspirone (5 mg/kg, i.p) and its interaction with $\mathrm{Mg}(50 \mathrm{mg} / \mathrm{kg})$ was evaluated after ten days treatment. Mg given at all doses (50, 100 and $200 \mathrm{mg} / \mathrm{kg}$ ) and buspirone ( $5 \mathrm{mg} / \mathrm{kg}$ ) induced an anxiolytic-like effect significantly increasing the percentage of the time spent in the open arms (\%OAT), the percentage of the open arm entries (\%OAE) and number of total entries. Percent time spend in open arms was reduced when buspirone coadministered with $\mathrm{Mg}(50 \mathrm{mg} / \mathrm{kg})$ compared to $\mathrm{Mg}$ alone. However, the number of entries did not change significantly. No synergistic interaction (increased time in open arms and number of open arm entries) between Mg and buspirone was observed, in this test, on the contrary, \%0AT preserved about buspirone effects and \%OAE remained around Mg effect. The obtained data indicate that Mg may act partly via serotonergic receptors due to buspirone's inhibitory action as a partial agonist of serotonin receptor.
\end{abstract}

\section{Keywords}

Anxiety, Magnesium Chloride, Buspirone, Mice

\section{Introduction}

Anxiety disorders are a group of mental diseases characterized by excessive feelings of anxiety and fear, where

${ }^{*}$ Corresponding author.

How to cite this paper: Jahromy, M.H., Golbaghi, G., Mohajer, A.J., Poor, F.K. and Riazi, M. (2014) Effects of Buspirone on Anxiolytic Effects of Magnesium in Male Mice. Pharmacology \& Pharmacy, 5, 657-662.

http://dx.doi.org/10.4236/pp.2014.57075 
anxiety is worry about future events and fear is a reaction to current events. These feelings may cause physical symptoms such as a racing heart and shakiness [1]. Anxiety disorders are partly genetic but may also be due to drug use including alcohol and caffeine. They often occur with other mental disorders. Common treatment options include lifestyle changes, therapy, and medications. Medications are typically recommended only if other measures are not effective [2].

Low levels of GABA, a neurotransmitter that reduces activity in the central nervous system, contribute to anxiety. A number of anxiolytics achieve their effect by modulating the GABA receptors [3]. Selective serotonin reuptake inhibitors, the drugs most commonly used to treat depression, are frequently considered as a first line treatment for anxiety disorders [4].

Buspirone is an anxiolytic psychoactive drug of the azapirone chemical class. It is primarily used to treat generalized anxiety disorder (GAD). Unlike most drugs predominately used to treat anxiety, buspirone's pharmacology is not related to benzodiazepines or barbiturates, and so does not carry the risk of withdrawal symptoms when discontinued [5].

Buspirone functions as a serotonin $5-\mathrm{HT}_{1 \mathrm{~A}}$ receptor partial agonist. This action is thought to mediate its anxiolytic and antidepressant effects. Additionally, it functions as a presynaptic dopamine antagonist at the D2, D3 and D4 [6] receptors. Buspirone is also a partial $\alpha 1$ receptor agonist. The ability of buspirone to selectively block presynaptic mesolimbic D2 autoreceptors in lower doses appears to result in increased dopamine synthesis and release [7].

Buspirone's efficacy is comparable to that of members of the benzodiazepine family in treating GAD, although it tends to have a delayed onset of action [8]. It may take several weeks before buspirone's anxiolytic effects become noticeable, and many patients may also need a higher dosage to adequately respond to treatment. $[6]$.

Abrupt discontinuation of diazepam after 6 weeks of continuous administration resulted in withdrawal symptoms. This was not the case when administration of buspirone was ceased [9].

Magnesium (Mg) is an essential intracellular bioelement which plays an important role in a wide variety of metabolic reactions, in particular energy-requiring processes [10]. In the central nervous system (CNS) it is involved in signal transmission. Several studies have demonstrated that acute and chronic administration of Mg reduces immobility time in the forced swimming test (FST) in mice and rats, and enhances the anti-immobility activity of imipramine in this model [11]-[13]. Effects of other bivalent cationic metals such as calcium [14] and zinc [15] on anxiety have been also investigated, although their results showed preliminary anxiolytic effects. However, magnesium has been among the most predominant metal in central nervous system to affect neurotransmission.

Recently, an indication that the serotoninergic system is involved in the antidepressant-like effect of Mg was given by the fact that the pre-treatment of mice with an inhibitor of serotonin synthesis, p-chlorophenylalanine was able to reduce the anti-immobility effect of magnesium in the FST [16] [17].

Therefore, it is important to investigate the involvement of $\mathrm{Mg}$ in the mechanism of anxiolytic drug action. In this study, we investigated the interaction between $\mathrm{Mg}$ and commonly accepted anxyolitic drug, buspirone as a partial agonist of 5- $\mathrm{HT}_{1 \mathrm{~A}}$ receptors, in producing anxiolytic-like activity in the elevated plus maze in mice.

\section{Materials and Methods}

Forty two Male adult mice weighing $23 \pm 2$ g (Pasteur Institute, Karaj Production and Research Center, Iran) were used in this study. The animals were randomly divided into six groups of seven each and treated according to the experimental protocol for ten days. Animals housed under the following laboratory conditions: temperature $22^{\circ} \mathrm{C} \pm 1{ }^{\circ} \mathrm{C}$, humidity 40\% - 60\%, $12 \mathrm{~h} \mathrm{Light/Dark} \mathrm{cycle,} \mathrm{lights} \mathrm{on} \mathrm{at} \mathrm{07:00} \mathrm{h.} \mathrm{Mice} \mathrm{were} \mathrm{maintained} \mathrm{in}$ polyethylene cages with enough food and water available ad libitum. All measurements were performed between 9:00 and 15:00 h in the animal testing room. Mice were treated by the current law of Medical Sciences Research Center, Tehran Medical Sciences Branch, Islamic Azad University, Tehran, Iran, in accordance with the National Institutes of Health (NIH) Guide for Care and Use of Laboratory Animals. Mg (magnesium Chloride Hexahydrate 98\%, DAE JUNG, Korea), was administered at doses 50, 100 and $200 \mathrm{mg} / \mathrm{kg} / \mathrm{day}$, orally. Control Group received distilled water orally. Buspirone (5 mg/kg, i.p) and its combination with mg (50 mg/kg) were administered in two separate groups.

The studies were carried out on mice according to the method of Lister [18]. The plus-maze apparatus was made of Plexiglas and consisted of two open $(30 \times 5 \mathrm{~cm})$ and two closed $(30 \times 5 \times 15 \mathrm{~cm})$ arms. The arms ex- 
tended from a central platform of $5 \times 5 \mathrm{~cm}$. The apparatus was mounted on a Plexiglas base raising it $38.5 \mathrm{~cm}$ above the floor. The test consisted in placing a mouse in the center of the apparatus (facing a closed arm) and allowing it to freely explore. The number of entries into the open arms and the time spent in these arms were scored for a 5-min test period. An entry was defined as placing all four paws within the boundaries of the arm. The following measures were obtained from the test: the total number of arm entries; the percentage of arm entries into the open arms; the time spent in the open arms expressed as a percentage of the time spent in both the open and closed arms. Anxiolytic activity was indicated by increases in time spent in open arms or in number of open arm entries. Total number of entries into either type of arm was used as a measure of overall motor activity.

All values were expressed as mean \pm SEM from seven animals. The results were subjected to statistical analysis by using Unpaired-t test to calculate the significance difference if any among the groups. $\mathrm{P}<0.05$ was considered significant.

\section{Results}

Mg given at all doses (50, 100 and $200 \mathrm{mg} / \mathrm{kg}$ ) induced an anxiolytic-like effect significantly increasing the percentage of the time spent in the open arms, and the percentage of the open arm entries and number of total entries (Figures 1-3, respectively). The increase in the percentage of the time spent in the open arms induced by $\mathrm{Mg} 50$ and $100 \mathrm{mg} / \mathrm{kg}$ was higher when compared to the maximum Mg dose used, although not significant. Buspirone ( $5 \mathrm{mg} / \mathrm{kg}$ ) showed anxiolytic effect after ten days, however, its effect on percent time spend in open arms, were lower that $\mathrm{Mg}$ ( $50 \mathrm{mg} / \mathrm{kg}$ ), while roughly comparable to the effect of $\mathrm{Mg} 200 \mathrm{mg} / \mathrm{kg}$. In combination with $\mathrm{Mg}$ (50 g/kg), buspirone did not produce more effect compared to buspirone, in other words, the combination effect was lower than $\mathrm{Mg} 50 \mathrm{mg} / \mathrm{kg}$, alone (Figure 1).

Buspirone given at a dose of $5 \mathrm{mg} / \mathrm{kg}$ for ten days induced an anxiolytic-like effect significantly increasing the percentage of the open arm entries (Figure 2). The increase was less than effects observed by $\mathrm{Mg}$ at all doses. However, binary application of buspirone $(5 \mathrm{mg} / \mathrm{kg})$ and $\mathrm{Mg}(50 \mathrm{mg} / \mathrm{kg})$ was significantly more than buspirone, alone, and somehow $\mathrm{Mg}(50 \mathrm{mg} / \mathrm{kg})$ effect, preserved.

Number of total entries increased significantly when buspirone used, however, in combination with $\mathrm{Mg} 50$ $\mathrm{mg} / \mathrm{kg}$, did not change compared to buspirone alone.

\section{Discussion}

Effects of 5- $\mathrm{HT}_{\mathrm{IA}}$ receptor agonist and NMDA receptor antagonist in the social interaction test and the elevated

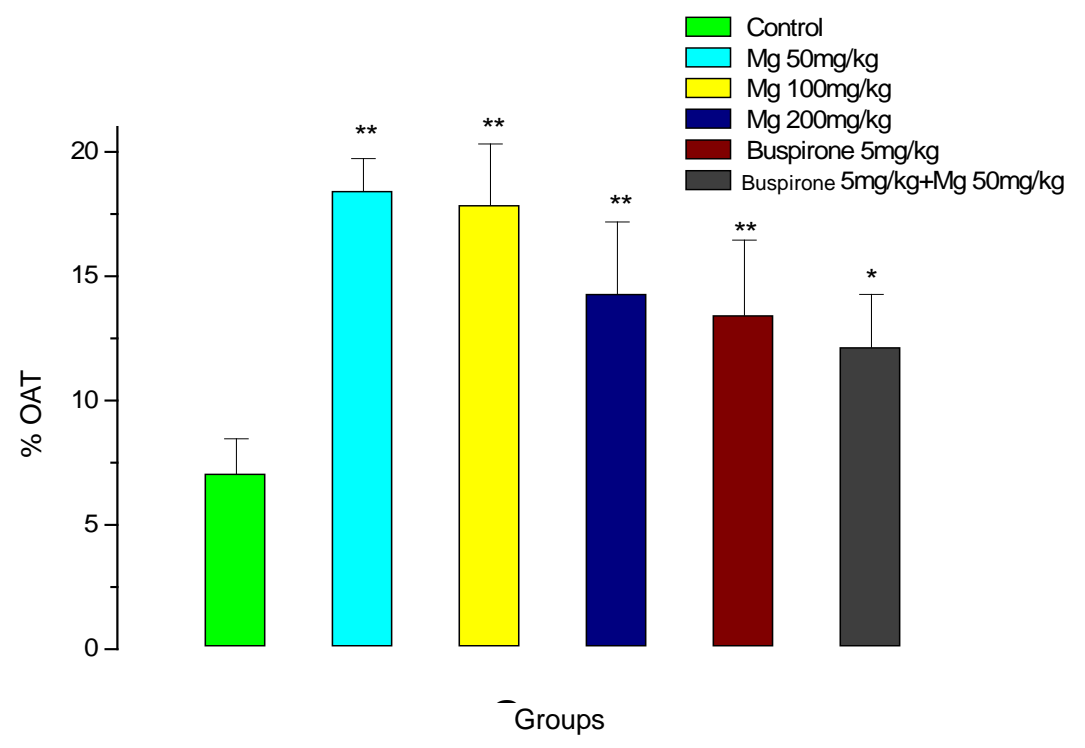

Figure 1. Percentage of time spent in open arms for magnesium (Mg), Buspirone and their interaction in the elevated plus-maze procedure in mice. The values represent the means \pm SEM $(n=7) .{ }^{*} \mathrm{P}<0.05,{ }^{* *} \mathrm{P}<0.01$ compared to control. 


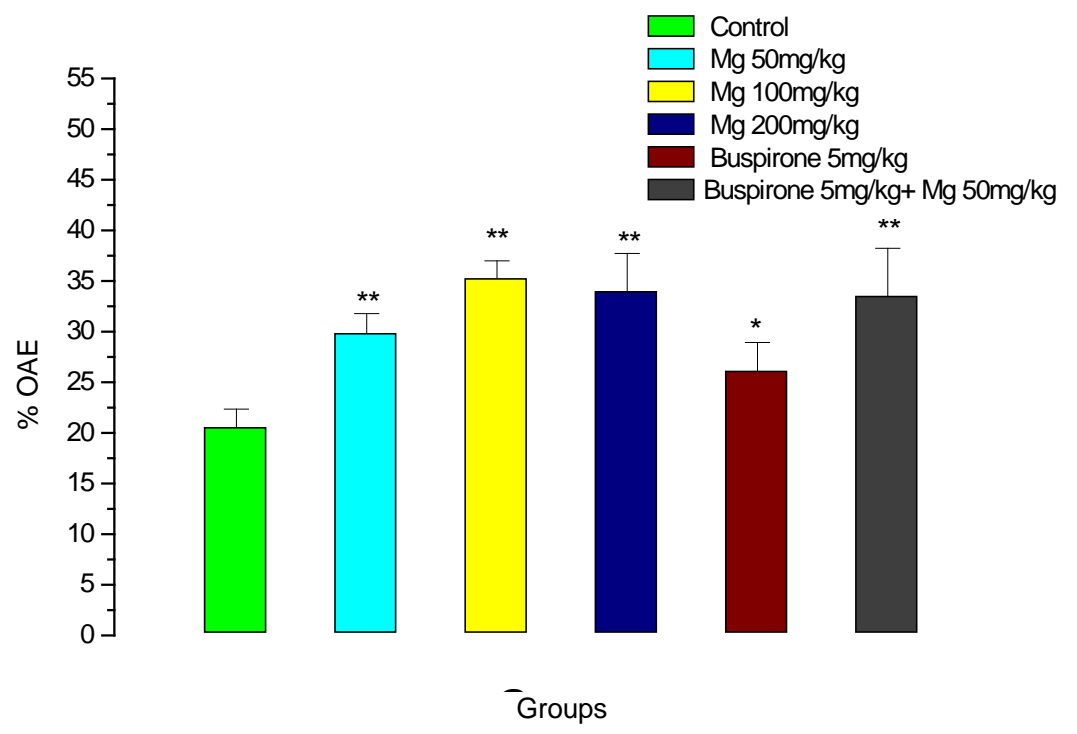

Figure 2. Percentage of open arms entries for magnesium (Mg), buspirone and their interaction in the elevated plus-maze procedure in mice. The values represent the means \pm SEM $(n=7) .{ }^{*} \mathrm{P}<0.05,{ }^{* *} \mathrm{P}<0.01$ compared to control.

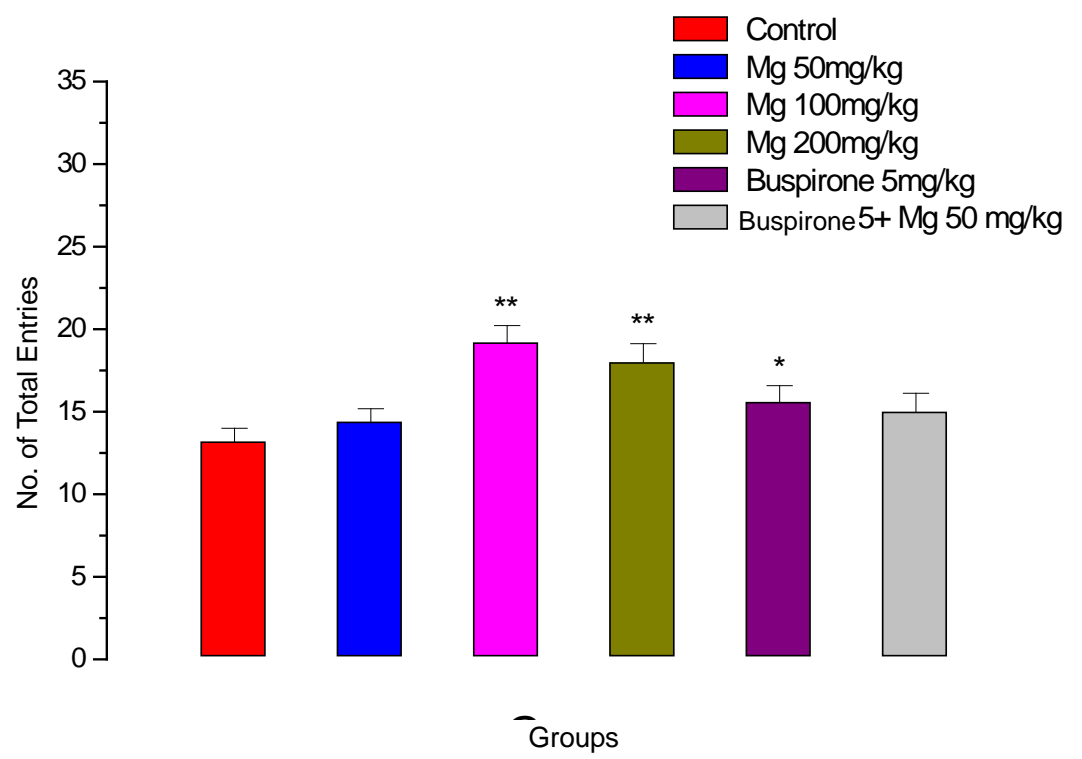

Figure 3. Number of total entries for magnesium (Mg), Buspirone and their interaction in the elevated plus-maze procedure in mice. The values represent the means \pm $\operatorname{SEM}(\mathrm{n}=7) .{ }^{*} \mathrm{P}<0.05,{ }^{* *} \mathrm{P}<0.01$ compared to control.

plus maze has been tested [19]. Some evidence showed that anxiolytic-like activity of Mg in EPM test involves GABA-ergic neurotransmission and indicated that benzodiazepine receptors are involved in the anxiolytic-like effects of Mg [20].

The present study investigated the interaction between $\mathrm{Mg}$ and commonly accepted anxyolitic drug, buspirone as a partial agonist of $5-\mathrm{HT}_{1 \mathrm{~A}}$ receptors, in producing anxiolytic-like activity in the elevated plus maze in mice.

It is reported that the administration of magnesium salts produces an antidepressant-like effect in the FST, a widely-accepted behavioral model predictive of antidepressant activity that is sensitive to all major classes of antidepressant drugs including tricyclics, serotonin-specific reuptake inhibitors, monoamine oxidase inhibitors and atypicals. Of most importance, results clearly demonstrated the involvement of the monoaminergic system in the antidepressant-like effect of $\mathrm{MgCl}_{2}$ in the FST and also, the synergistic antidepressant-like effect of 
$\mathrm{MgCl}_{2}$ administration with antidepressants from different classes: fluoxetine, imipramine or bupropion. Interaction of imipramine, citalopram, reboxetine and tianeptine with $\mathrm{Mg}^{2+}$ was also examined and a synergistic antidepressant-like effect of $\mathrm{Mg}^{2+}$ was shown only with imipramine, citalopram and tianeptine [12] [13] [16] [17]. Therefore interaction of $\mathrm{Mg}$ with serotonergic system seems to be important and need for consideration in order to predict their net effect in combinations used.

In the present study, the involvement of 5- $\mathrm{HT}_{1 \mathrm{~A}}$ receptors in the anxiolytic-like effect of $\mathrm{Mg}$ was indicated by the results showing that treatment of mice with buspirone prevented effects of Mg in the EPM test. From the pharmacological point of view, buspirone as a partial agonist, in presence of Mg (if consider as a 5-HT agonist) showed competitive antagonistic effects. However, the selective $5-\mathrm{HT}_{1 \mathrm{~A}}$ receptor antagonist should be tested to confirm this study. Overall, this experiment partly indicates that the 5- $\mathrm{HT}_{1 \mathrm{~A}}$ receptor could be relevant for the anxiolytic action of this ion in the EPM test.

\section{Conclusion}

The present study extends literature data about mechanisms underlying the anxiolytic-like effect of $\mathrm{Mg}$ in the EPM test. We have shown that its anxyolitic-like effect is partly dependent on its interaction with the serotonergic $\left(5-\mathrm{HT}_{1 \mathrm{~A}}\right)$ systems. In fact, the reduction in anxiolytic-like effect obtained when mice were treated with $\mathrm{Mg}$ in combination with buspirone has reinforced the hypothesis of the involvement of the serotonergic system in the mechanism of the anxiolytic-like action of magnesium. Of course, more studies need to be designed using specific antagonists to reveal exact interactions.

\section{Acknowledgements}

The research was supported by the grant (No. 43335) from the Research Deputy of Islamic Azad University, Tehran Medical Sciences Branch, Tehran, Iran. Authors would like to thank Dr. Ghorbani Yekta, Mr. Shafikhani and Ms. Hashemi for their help during experimental work.

\section{References}

[1] (2013) Diagnostic and Statistical Manual of Mental Disorders American Psychiatric Association, 5th Edition, American Psychiatric Publishing, Arlington, 189-195.

[2] Patel, G. and Fancher, T.L. (2013) In the Clinic. Generalized Anxiety Disorder. Annals of Internal Medicine, 159, 1-11. http://dx.doi.org/10.7326/0003-4819-159-11-201312030-01006

[3] Lydiard, R.B. (2003) The Role of GABA in Anxiety Disorders. Journal of Clinical Psychiatry, 64, 21-27.

[4] Dunlop, B.W. and Davis, P.G. (2008) Combination Treatment with Benzodiazepines and SSRIs for Comorbid Anxiety and Depression: A Review. Prim Care Companion. Journal of Clinical Psychiatry, 10, 222-228. http://dx.doi.org/10.4088/PCC.v10n0307

[5] Fulton, B. and Brogden, R.N. (1997) Buspirone. CNS Drugs, 7, 68-88. http://dx.doi.org/10.2165/00023210-199707010-00007

[6] Buspirone Monograph. Drugs.com.

[7] Jadhav, S.A., Gaikwad, R.V., Gaonkar, R.K., Thorat, V.M., Gursale, S.C. and Balsara, J.J. (2008) Dose-Dependent Response of Central Dopaminergic Systems to Buspirone in Mice. Indian Journal of Experimental Biology, 46, 704714.

[8] Cohn, J.B., Rickels, K. and Steege, J.F. (1989) A Pooled, Double-Blind Comparison of the Effects of Buspirone, Diazepam and Placebo in Women with Chronic Anxiety. Current Medical Research and Opinion, 11, 304-320. http://dx.doi.org/10.1185/03007998909115213

[9] Murphy, S.M., Owen, R. and Tyrer, P. (1989) Comparative Assessment of Efficacy and Withdrawal Symptoms after 6 and 12 Weeks' Treatment with Diazepam or Buspirone. The British Journal of Psychiatry: The Journal of Mental Science, 154, 529-534.

[10] Ryan, M.F. (1991) The Role of Magnesium in Clinical Biochemistry: An Overview. Annals of Clinical Biochemistry, 28, 19-26. http://dx.doi.org/10.1177/000456329102800103

[11] Cardoso, C.C., Lobato, K.R., Binfaré, R.W., Ferreira, P.K., Rosa, A.O., Santos, A.R.S. and Rodrigues, A.L.S. (2009) Evidence for the Involvement of the Monoaminergic System in the Antidepressant-Like Effect of Magnesium. Progress in Neuro-Psychopharmacology \& Biological Psychiatry, 33, 235-242.

http://dx.doi.org/10.1016/j.pnpbp.2008.11.007 
[12] Poleszak, E., Szewczyk, B., Kêdzierska, E., Wlaź, P., Pilc, A. and Nowak, G. (2004) Antidepressant- and AnxiolyticLike Activity of Magnesium in Mice. Pharmacology Biochemistry and Behavior, 78, 7-12. http://dx.doi.org/10.1016/j.pbb.2004.01.006

[13] Poleszak, E., Wlaź, P., Kêdzierska, E., Nieoczym, D., Wyska, E., Szymura-Oleksiak, J., Fidecka, S., et al. (2006) Immobility Stress Induces Depression-Like Behavior in the Forced Swim Test in Mice: Effect of Magnesium and Imipramine. Pharmacological Research, 58, 746-752.

[14] Hiremath, Sh.B., Anand, S., Srinivas, L.D. and Rashed, M.R. (2010) Effect of Calcium on Anxiolytic Activity of Diazepam and Verapamil in Rats. Indian Journal of Pharmacology, 42, 406-408. http://dx.doi.org/10.4103/0253-7613.71889

[15] Joshi, M., Akhtar, M., Najmi, A.K., Khuroo, A.H. and Goswami, D. (2012) Effect of Zinc in Animal Models of Anxiety, Depression and Psychosis. Human \& Experimental Toxicology, 31, 1237-1243. http://dx.doi.org/10.1177/0960327112444938

[16] Poleszak, E., Wlaź, P., Kêdzierska, E., Nieoczym, D., Wróbel, A., Fidecka, S. and Pilc, A. (2007) Nowak G: NMDA/ Glutamate Mechanism of Antidepressant-Like Action of Magnesium in Forced Swim Test in Mice. Pharmacology Biochemistry and Behavior, 88, 158-164. http://dx.doi.org/10.1016/j.pbb.2007.07.018

[17] Poleszak, E., Wlaź, P., Wróbel, A., Dybala, M., Sowa, M., Fidecka, S., Pilc, A. and Nowak, G. (2007) Activation of the NMDA/Glutamate Receptor Complex Antagonizes the NMDA Antagonist-Induced Antidepressant-Like Effects in the Forced Swim Test. Pharmacological Research, 59, 595-600.

[18] Lister, R.G. (1987) The Use of a Plus-Maze to Measure Anxiety in the Mouse. Psychopharmacology, 92, 180-185. http://dx.doi.org/10.1007/BF00177912

[19] Dunn, R.W., Corbett, R. and Fielding, S. (1989) Effects of 5-HT $\mathrm{HA}_{\mathrm{IA}}$ Receptor Agonist and NMDA Receptor Antagonist in the Social Interaction Test and the Elevated plus Maze. European Journal of Pharmacology, 169, 1-10. http://dx.doi.org/10.1016/0014-2999(89)90811-X

[20] Poleszak, E. (2008) Benzodiazepine/GABAA Receptors Are Involved in Magnesium-Induced Anxiolytic-Like Behavior in Mice. Pharmacological Reports, 60, 483-489. 